\title{
KEEFEKTIFAN MODEL COOPERATIVE LEARNING TIPE STUDENT FACILITATOR AND EXPLAINING PADA MATA PELAJARAN AKUNTANSI
}

\author{
Siti Ma'rifah ${ }^{1)}$, Neni Hendaryati ${ }^{2)}$ \\ Pendidikan Ekonomi, FKIP, Universitas Pancasakti \\ sitimarifah@gmail.com ${ }^{1)}$, neni.pefkip@gmail.com ${ }^{2)}$
}

\begin{abstract}
The purpose of this research was to determine the effectiveness of cooperative learning model type student facilitator and explaining on accounting subjects in class XI Accounting of SMK 1 Dukuhturi. A quantitative approach with the quasi experimental design used in this research. The population is 180 students. The sampling technique used purposive cluster sampling and obtained two classes or as many as 72 students who were used as research samples. The t test is used to analyze data collected through observation, tests and documentation. The results showed that the calculation of the t test was $6.01\left(t_{\text {count }}=6.01\right)$. With degrees of freedom $(\mathrm{dk})=36+36-2=70$, the significance level is $5 \%$ and the price is $t_{\text {table }}=2,000$. This can be interpreted $t_{\text {count }}>t_{\text {table }},(6.01>2,000)$, so this research states that the cooperative learning model type student facilitator and explaining is effective to be used in accounting subjects in class XI Accounting of SMK 1 Dukuhturi. The effectiveness of using this model is one of the creative learning alternatives that can be applied in schools.
\end{abstract}

Keywords : Cooperative Learning, Student Facilitator And Explaining

\begin{abstract}
Abstrak
Tujuan penelitian ini untuk mengetahui keefektifan model cooperative learning tipe student facilitator and explaining pada mata pelajaran akuntansi kelas XI Akuntansi SMKN 1 Dukuhturi. Pendekatan kuantitatif dengan quasi eksperimental design digunakan dalam penelitian ini. Populasi sebanyak 180 siswa. Teknik pengambilan sampel menggunakan purposive cluster sampling dan diperoleh dua kelas atau sebanyak 72 siswa yang dijadikan sampel penelitian. Uji t digunakan untuk menganalisis data yang dikumpulkan melalui observasi, tes dan dokumentasi. Hasil penelitian menunjukkan perhitungan uji t sebesar 6,01 $\left(\mathrm{t}_{\text {hitung }}=6,01\right)$. Dengan derajat kebebasan $(\mathrm{dk})=36+36-2=70$, taraf signifikansi $5 \%$ dan harga $t_{\text {tabel }}=2,000$. Hal ini dapat diartikan $t_{\text {hitung }}>t_{\text {tabel }},(6,01>2,000)$, maka penelitian ini menyatakan bahwa model pembelajaran kooperatif tipe student facilitator and explaining efektif digunakan pada mata pelajaran akuntansi kelas XI Akuntansi SMKN 1 Dukuhturi. Keefektifan penggunaan model tersebut menjadi salah satu alternatif pembelajaran kreatif yang dapat diterapkan di sekolah.
\end{abstract}

Kata kunci: Cooperative Learning, Student Facilitator And Explaining. 


\section{PENDAHULUAN}

Mengajar yang efektif ialah mengajar yang dapat membawa belajar peserta didik yang efektif pula (Slameto, 2010:92). Agar menjadi efektif, guru tidak lagi menjadi center dalam proses pembelajaran. Guru hendaknya menerapkan berbagai jenis model atau metode mengajar dalam kelas. Dimaksudkan supaya tercipta suasana belajar mengajar yang menyenangkan sekaligus efektif tanpa mengabaikan pokok-pokok pelajaran. Pembelajaran efektif terjalin antara guru dan siswa yang secara sadar harus tercipta interaksi saling asuh (saling tegang rasa) serta menjalin kerja sama untuk mencapai tujuan pembelajaran (Hamdani, 2010:30).

Dewasa ini banyak dikembangkan model pembelajaran kreatif yang bertujuan untuk meningkatkan kualitas belajar mengajar. Salah satu model pembelajaran yang dapat menimbulkan hubungan timbal balik (interaksi) antara guru dan siswa adalah cooperative learning. Mutmainah (2008) menyatakan bahwa pembelajaran kooperatif berbasis kasus yang berpusat pada mahasiswa terhadap efektivitas pembelajaran akuntansi dapat mengoptimalkan potensi intelektual, sosial dan emosional mahasiswa. Namun tidak dipungkiri baru sebagian kecil guru yang menerapkan berbagai model pembelajaran di kelas mereka. Terutama pada pembelajaran akuntansi di SMK. Akuntansi menjadi pembelajaran yang mendapat predikat monoton dikalangan siswa SMKN 1 Dukuhturi Kabupaten Tegal. Pembelajaran akuntansi diisi dengan ceramah, diskusi, drill dan penugasan, hal ini dikarenakan guru sendiri menganggap bahwa materi-materi dalam akuntansi sulit disajikan sesuai kurikulum 2013 jika diterapkan dengan pembelajaran selain yang telah disebutkan sebelumnya. Implikasi dalam proses belajar mengajar siswa menjadi kurang aktif dan pembelajaran cenderung berpusat pada guru.
Nilai siswa yang belum mencapai KKM pun masih mendominasi.

Berikut data prestasi belajar siswa kelas XAK sebelum dilakukan treatment.

Tabel 1. Nilai awal siswa

\begin{tabular}{lcccc}
\hline No & Kelas & $\begin{array}{c}\text { Nilai } \\
\text { rata- } \\
\text { rata } \\
\text { kelas }\end{array}$ & $\begin{array}{c}\text { Persentase } \\
\text { Nilai } \\
\text { di atas } \\
\text { KKM (\%) }\end{array}$ & $\begin{array}{c}\text { Persentase } \\
\text { Nilai } \\
\text { di bawah } \\
\text { KKM(\%) }\end{array}$ \\
\hline 1 & X AK 1 & 63,11 & $22,2 \%$ & $77,8 \%$ \\
2 & X AK 2 & 65,78 & $33,3 \%$ & $66,7 \%$ \\
3 & X AK 3 & 65.02 & $27,7 \%$ & $72,3 \%$ \\
4 & X AK 4 & 67,45 & $38,8 \%$ & $61,2 \%$ \\
5 & X AK 5 & 63,02 & $22,2 \%$ & $77,8 \%$ \\
\hline
\end{tabular}

Sumber: Ulangan Harian Pokok Bahasan Neraca Saldo Kelas XAK

Dari data tersebut, lebih dari 50\% siswa di masing-masing kelas belum memenuhi nilai KKM yang dipersyaratkan. Terdapat dua kelas dengan nilai rata-rata terendah yaitu kelas X AK 1 dan X AK 5. Kedua kelas tersebut prosentase ketuntasan siswanya hanya 22,2\% saja. Artinya masih sekitar $77,8 \%$ siswa yang dinyatakan belum tuntas.

Muslim, Siska Ryane (2015) menyimpulkan hasil penelitiannya bahwa kemampuan pemecahan masalah matematik siswa yang mengikuti pembelajaran dengan menggunakan metode student facilitator and explaining lebih tinggi dibandingkan siswa yang mengikuti pembelajaran langsung. Dari uraian di atas dan mengacu pada beberapa rujukan, penelitian ini mencoba mengaplikasikan model pembelajaran kooperatif tipe SfaE yang biasa digunakan pada pembelajaran Matematika dan Sains, diterapkan pada pembelajaran akuntansi.

\section{METODE PENELITIAN}

Sesuai dengan tujuannya, pendekatan yang digunakan dalam penelitian ini adalah kuantitatif dengan desain quasi experimental. Populasi berjumlah 180 siswa terdiri dari 5 kelas X Akuntansi. Teknik pengambilan sampel menggunakan purposive cluster sampling tentu saja ini dikarenakan sampel diambil berdasarkan pertimbangan tertentu 
dengan mencari kelas yang memiliki karakteristik sama/hampir sama. Diambillah sampel sebanyak 72 siswa yang terdiri dari 36 siswa dikelas eksperimen dan 36 siswa di kelas kontrol.

Data dikumpulkan melalui observasi, tes dan dokumentasi. Uji coba instrumen dilakukan kepada 30 responden. Terdapat 25 butir soal pada instrumen tes, dengan uji taraf kesukaran diperoleh hasil sebagai berikut: terdapat 10 soal masuk dalam kriteria soal mudah atau sekitar 40\%, 12 soal berkategori soal sedang (48\%) dan 3 sisanya adalah soal sukar atau sebesar (12\%). Uji beda butir soal menghasilkan 5 soal berdaya beda baik, 15 soal berdaya beda cukup baik, dan 5 soal merupakan soal jelek. Maka berdasarkan hasil uji beda dan taraf kesukaran, hanya 20 soal yang digunakan sebagai instrumen.

Di samping instrumen diuji taraf kesukaran dan uji bedanya, uji validitas dan reliabilitas juga dilakukan pada instrumen tes yang akan digunakan untuk pengambilan data. Hasilnya, 25 butir soal diperoleh 5 soal yang dianggap tidak valid. Sedangkan reliabilitas soal menunjukkan $r_{\text {hitung }}(0,906)>$ $\mathrm{r}_{\text {tabel }}(0,361)$ maka termasuk dalam kategori sangat reliabel.

Pengujian hipotesis menggunakan uji t dengan rumus:

$$
\mathrm{t}=\frac{\overline{\mathrm{X}}_{1}-\overline{\mathrm{X}}_{2}}{\frac{\left(\mathrm{n}_{1}-1\right) \mathrm{S}_{1}{ }^{2}+\left(\mathrm{n}_{2}-1\right) \mathrm{S}_{2}{ }^{2}}{\mathrm{n}_{1}+\mathrm{n}_{2}-2}\left(\frac{1}{\mathrm{n}_{1}}+\frac{1}{\mathrm{n}_{2}}\right)}
$$

Sedangkan untuk kriteria pembelajaran efektif pada penelitian ini adalah apabila hasil belajar kelas eksperimen lebih tinggi dibandingkan kelas kontrol.

\section{HASIL DAN PEMBAHASAN}

Penelitian dilakukan pada siswa kelas X Akuntansi SMKN 1 Dukuhturi Kabupaten Tegal pada tahun pelajaran 2018/ 2019. Perlakuan penerapan model cooperative learning tipe student facilitator and explaining diberikan kepada kelas eksperimen dengan pertemuan sebanyak 3 kali. Hasil perhitungan statistik deskriptif menunjukkan nilai rata-rata kelas eksperimen sebesar 77,08 dengan skor tertinggi 95 dan skor terendah 50. Pencapaian ketuntasan belajar meningkat dari $22,2 \%$ menjadi $66,7 \%$ siswa di kelas eksperimen mencapai nilai KKM. Perolehan tersebut lebih tinggi dibandingkan nilai rata-rata kelas kontrol setelah pemberian post test yaitu 69,72 meskipun untuk skor tertinggi dan terendah sama dengan kelas eksperimen sebesar 95 dan 50. Hasil tersebut membuktikan bahwa kelas yang mendapat perlakuan (kelas eksperimen) siswanya memiliki pemahaman terhadap materi lebih tinggi dibandingkan kelas kontrol, sehingga prosentase ketuntasan minimal klasikalnya meningkat cukup signifikan.

Untuk menguji hipotesis, dilakukan uji $\mathrm{t}$ terhadap kedua kelas sampel. Hal ini bertujuan untuk mengetahui signifikansi perbedaan penerapan model pembelajaran. hasil perhitungan uji $\mathrm{t}$ menunjukkan nilai sebesar 6,0129 dengan taraf signifikansi 5\%. Sedangkan nilai $\mathrm{t}$ tabel sebesar 2,000 sehingga dapat dikatakan $\mathrm{t}_{\text {hitung }}>\mathrm{t}_{\text {tabel }}$ yaitu $6,0129>2,000$. Lebih jelasnya perhatikan tabel berikut:

Tabel 2. Rata-rata post test dan hasil t test

\begin{tabular}{lcccc}
\hline \multicolumn{1}{c}{ Variabel } & $\begin{array}{c}\text { Rata- } \\
\text { rata }\end{array}$ & $\mathbf{T}_{\text {hitung }}$ & $\mathbf{T}_{\text {tabel }}$ & Kriteria \\
\hline $\begin{array}{l}\text { Kelompok } \\
\text { Eksperimen } \\
\text { (Model }\end{array}$ & & & & \\
$\begin{array}{l}\text { Pembelajaran } \\
\text { Kooperatif tipe } \\
\text { student facilitator } \\
\text { and explaining) }\end{array}$ & 77,08 & & & \\
$\begin{array}{l}\text { Kelompok Kontrol } \\
\text { (Model }\end{array}$ & & 6,01 & 2,000 & $\begin{array}{l}\text { Ada } \\
\text { perbedaan }\end{array}$ \\
$\begin{array}{l}\text { pembelajaran } \\
\text { Konvensional) }\end{array}$ & 69,72 & & & \\
\hline
\end{tabular}

Dari tabel di atas, dapat disimpulkan bahwa "terdapat perbedaan keefektifan antara pembelajaran kooperatif tipe student 
facilitator and explaining dengan model pembelajaran yang menggunakan metode ceramah dan drill terhadap hasil belajar siswa kelas X Akuntansi di SMKN 1 Dukuhturi Kabupaten Tegal. Meningkatnya hasil belajar kelas eksperimen mengungguli hasil belajar kelas kontrol membuktikan bahwa model ini efektif diterapkan dalam mata pelajaran akuntansi. Hal ini memperkuat teori Nana Sudjana (1990: 50) yang mengartikan efektivitas dalam pembelajaran merupakan keberhasilan siswa untuk mencapai tujuan tertentu yang dapat membawa hasil belajar secara maksimal. Hasil belajar yang maksimal tentunya disebabkan oleh peningkatan pemahaman materi belajar siswa, sehingga pembelajaran dapat dikatakan sebagai hasil dari memori kognisi dan metakognisi yang berpengaruh terhadap pemahaman (Miftahul, 2014:2).

\section{PENUTUP}

\section{Simpulan}

Berdasarkan hasil penelitian dan pembahasan dapat disimpulkan bahwa nilai rata-rata hasil belajar kelas eksperimen lebih tinggi dari kelas kontrol yaitu 77,08 > 69,72 begitu pula uji hipotesis menyatakan $t_{\text {hitung }}$ lebih besar dari $t_{\text {tabel }}$ yaitu 6,0129>2,000. Dari kedua perbedaan tersebut maka model pembelajaran kooperatif tipe student facilitator and explaining efektif diterapkan pada pembelajaran akuntansi.

\section{Saran}

Saran diberikan bagi guru/dosen/ pengajar agar senantiasa menggunakan model pembelajaran kooperatif tipe Student
Facilitator and Explaining pada pembelajaran mata kuliah/mata pelajaran yang lainnya.

\section{DAFTAR PUSTAKA}

Mutmainah, Siti. (2008). Pengaruh Penerapan Metode Pembelajaran Kooperatif Berbasis Kasus yang Berpusat Pada Mahasiswa Terhadap Efektivitas Pembelajaran Akuntansi Keperilakuan. Simposium Nasional Akuntansi 11 Universitas Tanjungpura Pontianak.

Hamid, Hamdani. (2010). Pengembangan Sistem Pendidikan di Indonesia. Bandung: CV Pustaka Setia.

Slameto. (2010). Belajar dan Faktor-faktor yang Mempengaruhinya. Jakarta: PT Rineka Cipta.

Muslim, Siska Ryane. (2015). Pengaruh Penggunaan Metode Student Facilitator And Explaining dalam Pembelajaran Kooperatif Terhadap Kemampuan Pemecahan Masalah Matematik Siswa SMK di Kota Tasikmalaya. Jurnal Penelitian Pendidikan dan Pengajaran Matematika Vol. 1 No. 1 pp 65-72, September 2015.

Sudjana, Nana. (1990). Penilaian Hasil Proses Belajar Mengajar. Bandung: PT Remaja Rosdakarya.

Huda, Miftahul. (2014). Model-model Pembelajaran (Isu-isu Metodis dan Paradigmatis). Yogyakarta: Pustaka Pelajar. 